\title{
Measurement of composite resin filler particles by using scanning electron microscopy and digital imaging
}

\author{
Merle J. Jaarda, DDS, MS, ${ }^{\text {a Brien R. Lang, DDS, MS, }}{ }^{\text {b }}$ \\ Rui-Feng Wang, BS, ${ }^{c}$ and Chris A. Edwards, BS, MS ${ }^{\mathrm{d}}$ \\ The University of Michigan, School of Dentistry, Ann Arbor, Mich.
}

\begin{abstract}
Composite resins are routinely classified on the basis of filler particle size for purposes of research, clinical applications, and communications. The size and characterizations of filler particles have also been considered a significant factor in the rate of wear of composites. Making valid correlations between the filler particles within a composite and wear requires accuracy of filler particle size and characterization. This study was initiated to examine two methods that would (1) qualify the filler particle content of a composite resin and (2) quantify the number, size, and the area occupied by the filler particles in composite resins. Three composite resins, BIS-FIL I, Visio-Fil, and Ful-Fil, were selected as the materials to be examined, on the basis of their published composite classification type as fine particle. The findings demonstrated that scientific methods are available to examine qualitatively and measure quantitatively the composite resin filler particles in terms of their numbers, sizes, and area occupied by use of a scanning electron microscope and digital imaging. Significant differences in the filler particle numbers, sizes, and the area occupied were found for the three composite resins in this study that were classified as fine particle. (J PROSTHET DENT 1993;69:416-24.)
\end{abstract}

During the past two decades, composite resins have been suggested as substitutes for amalgam to restore posterior teeth because they offer the advantages of improved esthetics and do not contain mercury. However, marginal adaptation and occlusal wear are major clinical concerns with these materials. ${ }^{1,2}$ The resolution of these concerns requires scientific studies to examine the basic nature of wear. For example, it has been suggested that filler technology, particularly the composition, size, and area occupied by the filler particle within a composite resin formulation, has the potential to influence the wear performance of a composite resin. ${ }^{1.7}$ It has been reported that, "increasing the filler particle size will effectively modify not only the pattern of wear, but the rate of wear as well." 6 It has also been stated that the greater the size of the particle, the greater the potential for wear. ${ }^{6}$ Thus it would seem reasonable to expect several reports in the literature about correlations between filler particle size and wear. Perhaps the lack of such studies is because of the difficulty encountered in determining the exact size of the filler particles within a composite resin.

\footnotetext{
Supported by research grant DE from the National Institute of Dental Research, National Institutes of Health, Bethesda, Md. aAssistant Professor, Department of Prosthodontics.

bProfessor and Chairperson, Department of Prosthodontics.

'Research Associate I, Prosthodontic Research Laboratory.

${ }^{d}$ Research Associate II, Department of Biologic and Material Sciences.

Copyright $\odot 1993$ by The Editorial Council of THE JOURNAL OF Prosthetic Dentistry.

$0022-3913 / 93 / \$ 1.00+.10 \quad \mathbf{1 0} / \mathbf{1} / \mathbf{4 4 8 7 9}$
}

Most investigators classify composites according to particle size. However, it is apparent that tremendous variations exist for defining the average particle size or range of sizes of the particles for their material groupings. 1, 6, 8-10 Investigators have relied on information supplied by the manufacturer or other publications to classify composite resins. ${ }^{6,11,12}$ Unfortunately, most manufacturers' publications fail to provide the reader with the basis for their information or its accuracy. The scanning electron microscope (SEM) has been used to demonstrate qualitatively the filler particle content for classification purposes. However, the qualitative picture does not provide the data needed to classify the composite accurately on the basis of its filler particle content. If it is accepted that filler particles play a major role in controlling the properties of the composite resin as has been reported, ${ }^{6,13}$ then the filler particle content in terms of the number, sizes, and area occupied by the particles must be known if reliable correlations are to be drawn between the filler particle and wear.

To further illustrate the confusion that exists in the literature, two composite resins, Concise (3M, St. Paul, Minn.) and Visio-Fil (Espe-Premier, Norristown, Pa.), were considered. Concise has been described as a traditional composite resin with filler particles greater than 10 $\mu \mathrm{m} .{ }^{7}$ However, in another report, ${ }^{3}$ Concise was listed as a conventional composite with a particle size of $50 \mu \mathrm{m}$. Visio-Fil has been called a fine-particle composite, ${ }^{6}$ which means that its filler particle size was approximately $0.5 \mu \mathrm{m}$; yet in another report it has been classified as a macrofilled composite. ${ }^{7}$ Is Visio-Fil a macrofilled composite, or is it a fine-particle composite, and what are the filler particle sizes in this composite? A method that defines composites 
regarding the number and size of the particles and the area they occupy should be developed to determine the presence of correlations between the filler particle and clinical wear. In response, a study was initiated to examine two methods that would (1) qualify the filler particle content of a composite resin and (2) quantify the number, size, and area occupied by the filler particle in composite resins. Three composite resins, BIS-Fil I, Visio-Fil, and Ful-Fil, are listed in Table I and were selected on the basis of their published composite classification types ${ }^{6,11}$ as fine-particle materials. The experimental question to be addressed was that the three fine-particle composite resins selected do not differ with respect to number, sizes, and area occupied by their filler particles.

\section{MATERIAL AND METHODS}

The experiment was divided into two parts. The first part examined qualitatively the size of filler particles contained in the three composite resins with the SEM. The second part of the project used the SEM plus digital imaging to quantitatively measure the number, size, and area occupied by filler particles in composite samples.

For Part One, unpolymerized $0.5 \mathrm{gm}$ samples of the three materials, Visio-Fil, Ful-Fil, and BIS-Fil I, were suspended in $5 \mathrm{ml}$ of acetone and centrifuged for 2 minutes at $1000 \mathrm{rpm}$ to separate the filler particles from the matrix. This acetone washing process was repeated three times. The acetone and dissolved matrix substance were examined with the SEM to ensure that no filler particles were discarded with the solution. The filler particles that remained after washing were next placed in $5 \mathrm{ml}$ of chloroform for further washing and separation of the filler particles that clumped together as a result of the dissolution in acetone. This second solution that contained the filler particles and chloroform was centrifuged for 2 minutes at $1000 \mathrm{rpm}$, and the chloroform and residual matrix substance were examined by SEM to ensure the absence of filler particles before the solution was discarded. This chloroform washing process was also repeated three times. Finally, the remaining filler particles were suspended in $5 \mathrm{ml}$ of absolute ethanol and the suspended solution and filler particles were smeared on a glass slide in preparation for examination with the SEM. This method provided qualitative data as visual evidence of the range of filler particle sizes in each of the materials.

Part Two of this study used SEM and digital imaging to measure the filler particle content of the three composites. Three polymerized sample blocks, $10 \times 10 \times 2 \mathrm{~mm}$ in size, were prepared for each material according to the manufacturer's recommendations. These sample blocks were embedded in EXAKT 7200 Technovit medium (EXAKTKulzer, Norderstedt, Germany) in preparation for grinding of the sample surfaces before SEM examination. The surface selected for examination was at a level $200 \mu \mathrm{m}$ below the processed superior surface of each sample. The surface was prepared with a series of sandpaper disks and the EXAKT machining system, followed by polishing with a
Table I. Composite resins

\begin{tabular}{llll}
\hline Material & Classification & Manufacturer & $\begin{array}{c}\text { Method of } \\
\text { polymerization }\end{array}$ \\
\hline Visio-Fil & $\begin{array}{c}\text { Fine } \\
\text { particle }\end{array}$ & $\begin{array}{c}\text { Espe-Premier } \\
\text { Sales Corp. } \\
\text { Norristown, Pa. }\end{array}$ & Light-cured \\
BIS-FIL I & Fine & BISCO & Light-cured \\
& particle & Lombard, Ill. & \\
Ful-Fil & Fine & The L.D. Caulk & Light-cured \\
& particle & Division & \\
& \multicolumn{3}{c}{ Dentsply } \\
& \multicolumn{3}{c}{ International. } \\
& \multicolumn{3}{c}{ Inc. } \\
& & Milford, Del. \\
\hline
\end{tabular}

diamond paste. The surface was carbon-coated in preparation for SEM examination and digital imaging. The surface was divided into three equal sections, left to right, and a site in the center of each section was chosen for digitization, giving three sites in each block. Each sample site was examined and measured with the AMRAY 1000-B SEM (AMRAY Inc, Bedford, Mass.) and the Princeton GammaTech (PGT) 4 Plus digital imaging system, ${ }^{14}$ at $500 \times$ and $5000 \times$.

The PGT 4 Plus digital imaging systcm has a $012 \times 400$ pixel screen for the filler particle data. Each pixel in the image was digitized to a specific gray level. Once the gray scale was established for examination of the microstructure, the computer calculated all of the pixels that fell within the gray level range for that structure. This number divided by the total pixel count in the microscopic field provided the area fraction occupied by the filler particle, based on its gray level. The measurements were in square micrometers because the digital imaging system counts pixels. However, most published information on the classification of composites describes the size of the filler particle in micrometers. Unfortunately, what is actually measured is not reported, and it is assumed that the diameter of the particles is reported. In addition, from these published reports one also assumes that these particles are spherical. From the data in Part One, however, it was clearly demonstrated that these particles are not spherical (Figs. 1 through 3). Nevertheless, to compare the imaging data, as measured in square micrometers, with the published information on materials in a meaningful way, the particle size in square micrometers must be converted to micrometers, with the assumption that all particles are spherical.

To characterize the filler particle content of the composites studied, seven groups were established with specific filler-particle size groupings. An eighth category for the matrix was added to provide a measure of the percent of fill of the composite resin.

The filler particle size groupings were:

Group I. $0.11-0.50 \mu \mathrm{m}\left(0.0094 \leq 0.2 \mu \mathrm{m}^{2}\right)$ 


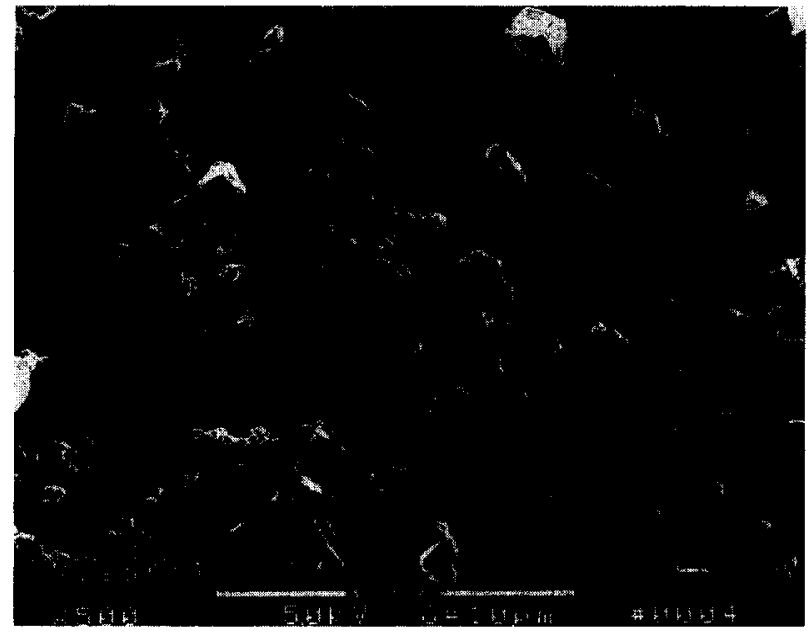

Fig. 1. Filler particles from Visio-Fil composite resin.

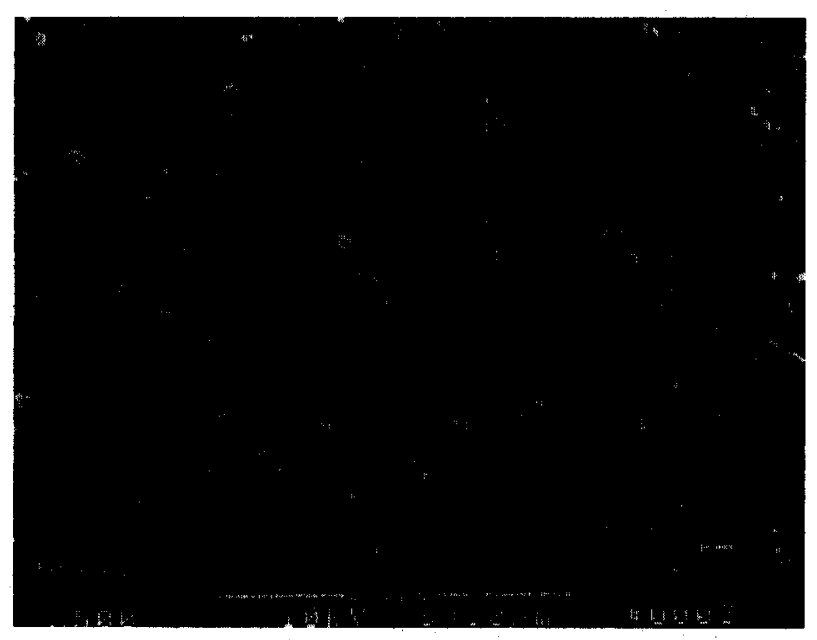

Fig. 2. Filler particles from BIS-FIL I composite resin.

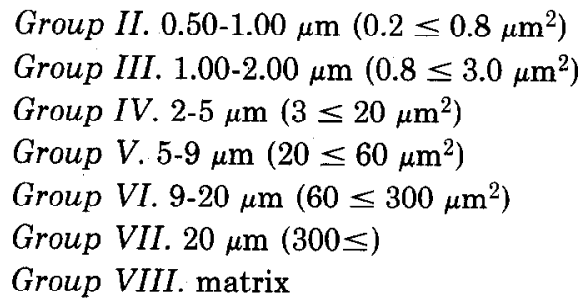

The number of filler particles in each of the groupings, the area of the particles in $\mu \mathrm{m}^{2}$, and the percentage of the examination field occupied by the filler particles were measured for each material for the several sites selected for the two magnifications $(\times 500$ and $\times 5000)$.

\section{RESULTS}

The filler particle sizes for the three composites as determined by the washing technique to remove the matrix materials and using the SEM are illustrated in Figs. 1 through 3 . Figs. 1 through 3 clearly demonstrate that the range of particle sizes and the individual filler particle size

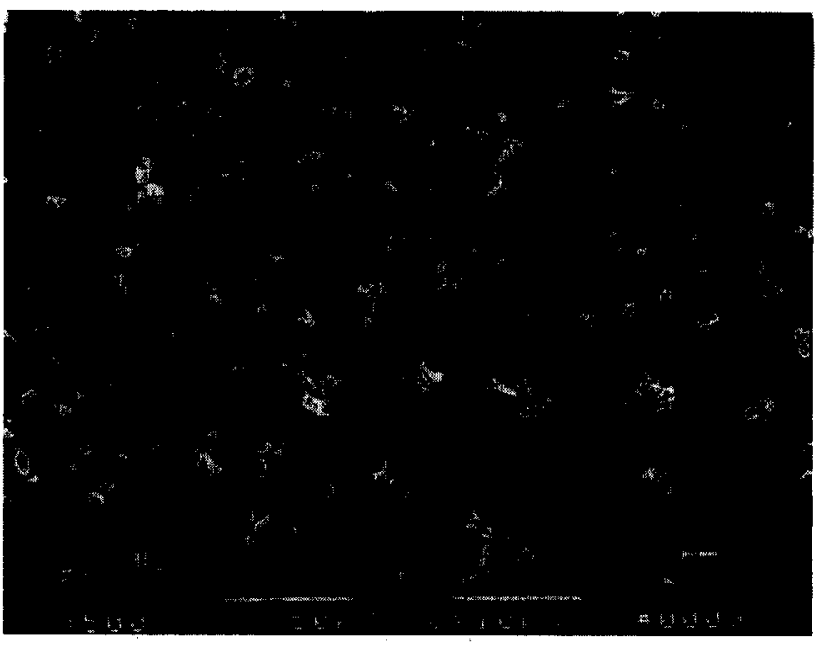

Fig. 3. Filler particles from Ful-Fil composite resin.

differences are dramatically different for each composite. No filler particles smaller than $0.11 \mu \mathrm{m}$ in diameter were found in the three composites. In Part Two of the study, the mean number of filler particles found in the seven groupings is shown in Figure 4. The mean area percentage occupied by the filler particles in the seven groupings and the matrix that comprises the eighth group are reported in Fig. 5. The mean number of particles in each group as a percentage of the total number of particles in each composite are reported in Fig. 6. In Fig. 7, the mean area percentage occupied by the seven particle groups without considering the matrix group is reported.

Tables II through $\mathrm{V}$ present the results of an ANOVA and a Tukey compromise test performed on the data found in Figs. 4 through 7. The ANOVA in Table II demonstrated a significant difference in the mean total number of particles for the three composite resins $(p<0.0005)$. A significant interaction was found between the materials and the mean number of particles for the composites studied $(p<0.0005)$. The Tukey compromise test in Table III demonstrated that the mean total number of filler particles in BIS-FIL I composite resin was significantly different from that of either Visio-Fil or Ful-Fil composite resins $(p<0.05)$. However, a significant difference was not found in the mean total number of particles between Visio-Fil and Ful-Fil composite resins $(p<0.05)$.

The ANOVA in Table IV demonstrates a significant difference in the mean total area occupied by the filler particles for the three composite resins $(p<0.0005)$. A significant interaction was found between the materials and the mean total area of the particles for the composites studied $(p<0.0005)$. The Tukey compromise test in Table V demonstrated that the mean total area of the filler particles in Visio-Fil material was significantly different from either BIS-FIL I or Ful-Fil composite resins $(p<0.05)$. However, a significant difference was not found in the mean total area of the particles between BIS-FIL I and Ful-Fil composite 


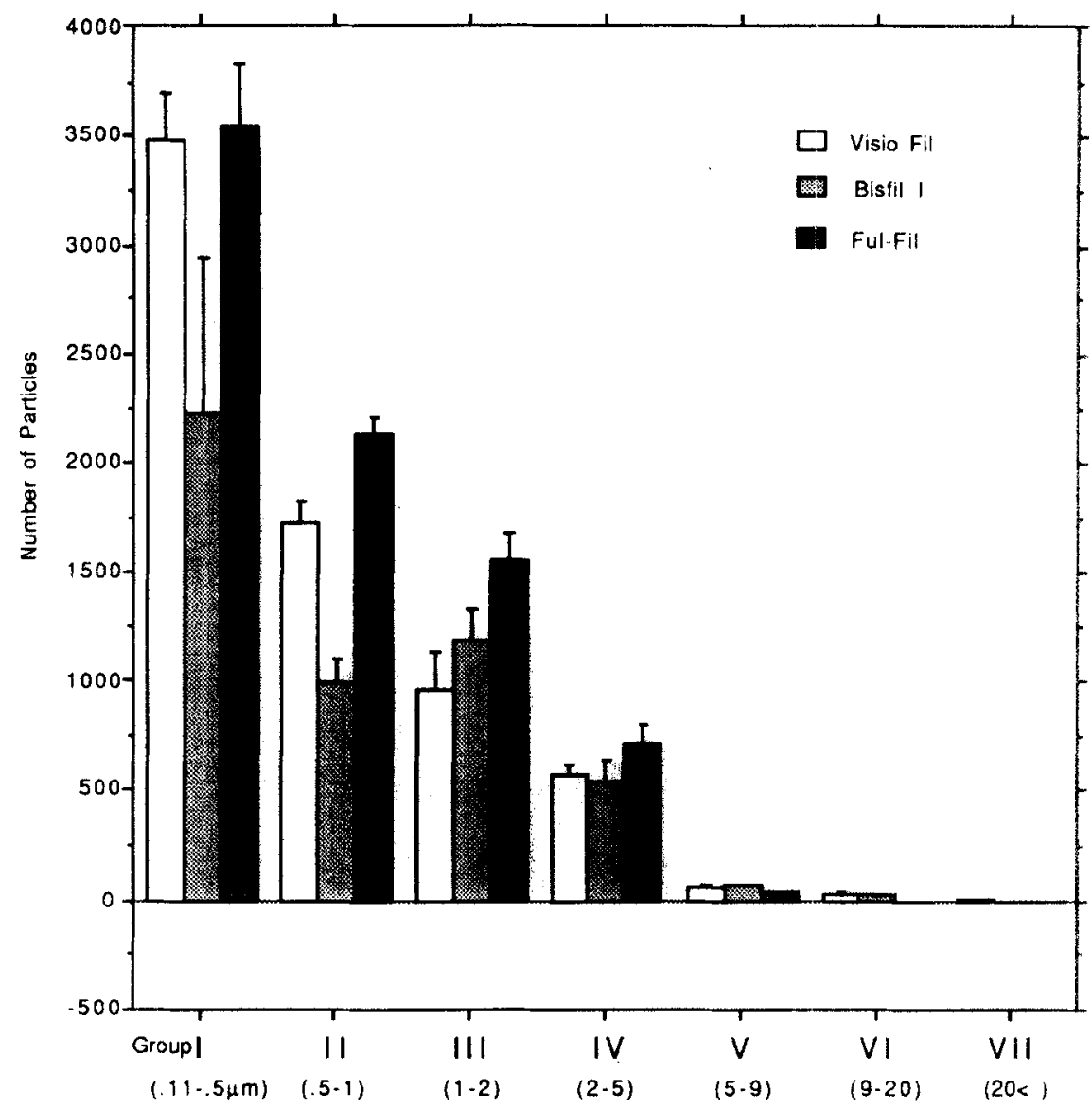

Fig. 4. Numbers of filler particles by material per group, with standard error bars.

resins $(p<0.05)$. An ANOVA and a Tukey compromise test were performed on the data in Figs. 4 through 7 to determine differences between materials in the mean numbers of particles and area occupied by the particles for the seven groupings of the composites studied.

In the mean number of filler particles in each group in Fig. 4, significant differences were found among all three materials for groups II and VI. In group II, Ful-Fil composite had the greatest mean number of particles and BIS-FIL I composite resin the fewest. In group VI, VisioFil composite had the greatest mean number of particles, and Ful-Fil composite had the fewest. No significant differences were found between materials for the mean number of particles in groups I and IV. In group III, VisioFil composite had significantly fewer mean number of par ticles than Ful-Fil composite. In group V, Ful-Fil composite had significantly fewer mean number of particles than Visio-Fil and BIS-FIL I composite resins. In group VII, Visio-Fil had significantly more mean number of particles than BIS-FIL I and Ful-Fil composite resins.

In the mean area occupied by the filler particles in each group in Fig. 5, significant differences were found among all three materials for groups II and VI. In group II, Ful-Fil composite had the largest mean area occupied by the particles and BIS-FIL I composite had the smallest mean area occupied by the particles. In group VI, Visio-Fil composite had the largest mean area occupied by the particles and Ful-Fil composite had the smallest. In group I, BIS-FIL I composite had a significantly smaller mean area occupied by the particles than either Visio-Fil or Ful-Fil composites. In group III, Ful-Fil composite had a significantly larger mean area occupied by the particles than Visio-Fil composite. In group IV, Ful-Fil composite had a significantly larger mean area occupied by the particles than either $\mathrm{Vi}$ sio-Fil or BIS-FIL I composites. In group V, Ful-Fil composite had a significantly smaller mean area occupied by the particles than either Visio-Fil or BIS-FIL I composites. In group VII, VisioFil composite had a significantly larger mean area occupied by the particles than BIS-FIL I or Ful-Fil composites. Visio-Fil composite had a significantly smaller mean area occupied by the matrix than either BISFIL I or Ful-Fil composites.

\section{DISCUSSION}

Since the introduction of composite resins by Bowen ${ }^{15}$ in 1962, clinicians, researchers, and manufacturers have sought ways to describe and communicate about these materials in terms of their filler particle content. The first such method was introduced in 1983, when Latz and Phillips ${ }^{8}$ presented their composite classification svstem, which was 

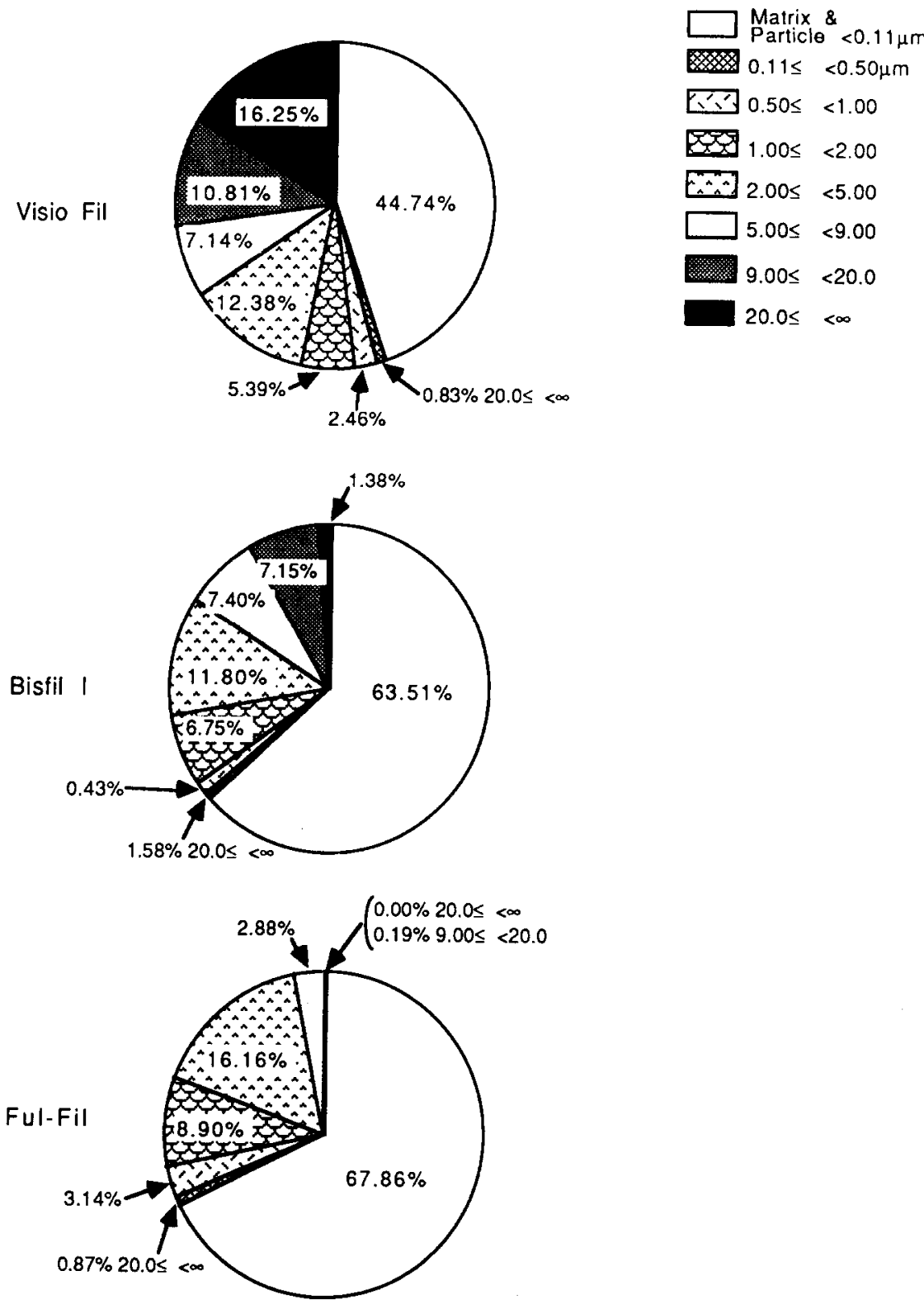

Fig. 5. Area occupied by matrix and different size particles.

Table II. ANOVA table on number differences

\begin{tabular}{lrrrrrl}
\hline \multicolumn{1}{c}{ Source } & df & Sum of squares & Mean square & F-Value & P-Value & Error term \\
\hline Material & 2 & 5724784.296 & 2862392.148 & 10.023 & 0.0001 & Residual \\
Material · block & 6 & 1865166.889 & 310861.148 & 1.088 & 0.3776 & Residual \\
Site (block, material) & 18 & 9239718.000 & 513317.667 & 1.651 & 0.2774 & Material $\cdot$ block \\
Number & 6 & 0.00000002106 & 0.0000003511 & 122.927 & 0.0001 & Residual \\
Material · number & 12 & 12092951.185 & 1007745.932 & 3.529 & 0.0004 & Residual \\
Number · block · material & 36 & 8279849.111 & 229995.809 & 0.448 & 0.9802 & Site (block, material) \\
Number · site (material) & 36 & 11752961.492 & 326471.153 & 0.636 & 0.8784 & Site (block, material) \\
Residual & 72 & 20562521.841 & 285590.581 & & & \\
\hline
\end{tabular}

Type I sums of squares. 

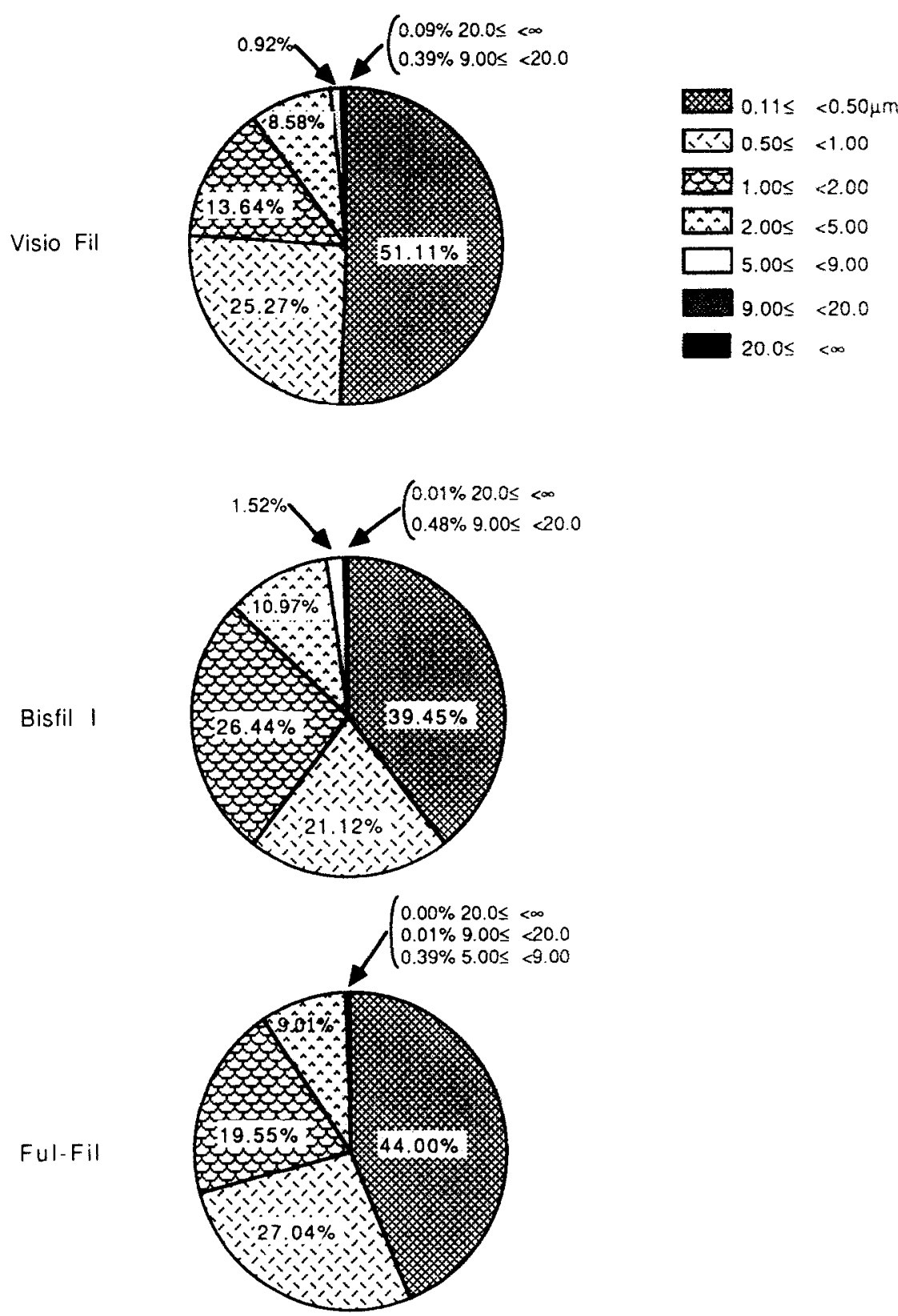

Fig. 6. Number of the different size particles.

based on average particle size, manufacturing techniques, and the chemical composition of the filler particles. Since then, other investigators have suggested other systems for describing the characteristics of these composites and a method of communication. The more commonly used systems in addition to the system by Lutz and Phillips, ${ }^{8}$ are the ones by Leinfelder, ${ }^{6}$ Roulet, ${ }^{1}$ Marshall et al., ${ }^{10}$ and recently Hosoda et al. ${ }^{9}$

The common elements in all the systems are the generic terms traditional, microfilled, fine particles, hybrid; yet, the descriptions or quantitative parameters for these terms are different from system to system. For example, the filler particle characterization of fine particle composites has been described as a material with an average particle size of $0.5 \mu \mathrm{m}$. This would seem to imply that fine-particle composites have filler particles within their formulations that would meet these "average" particle size specifications. It would also seem to indicate that the particles were measured before the material was classified as a fine-particle composite. Yet, often these kinds of determinations are missing in either promotional materials or research reports where a specific composite was studied.

The percentage by weight and/or volume of the filler particle content has also been considered as descriptive in 

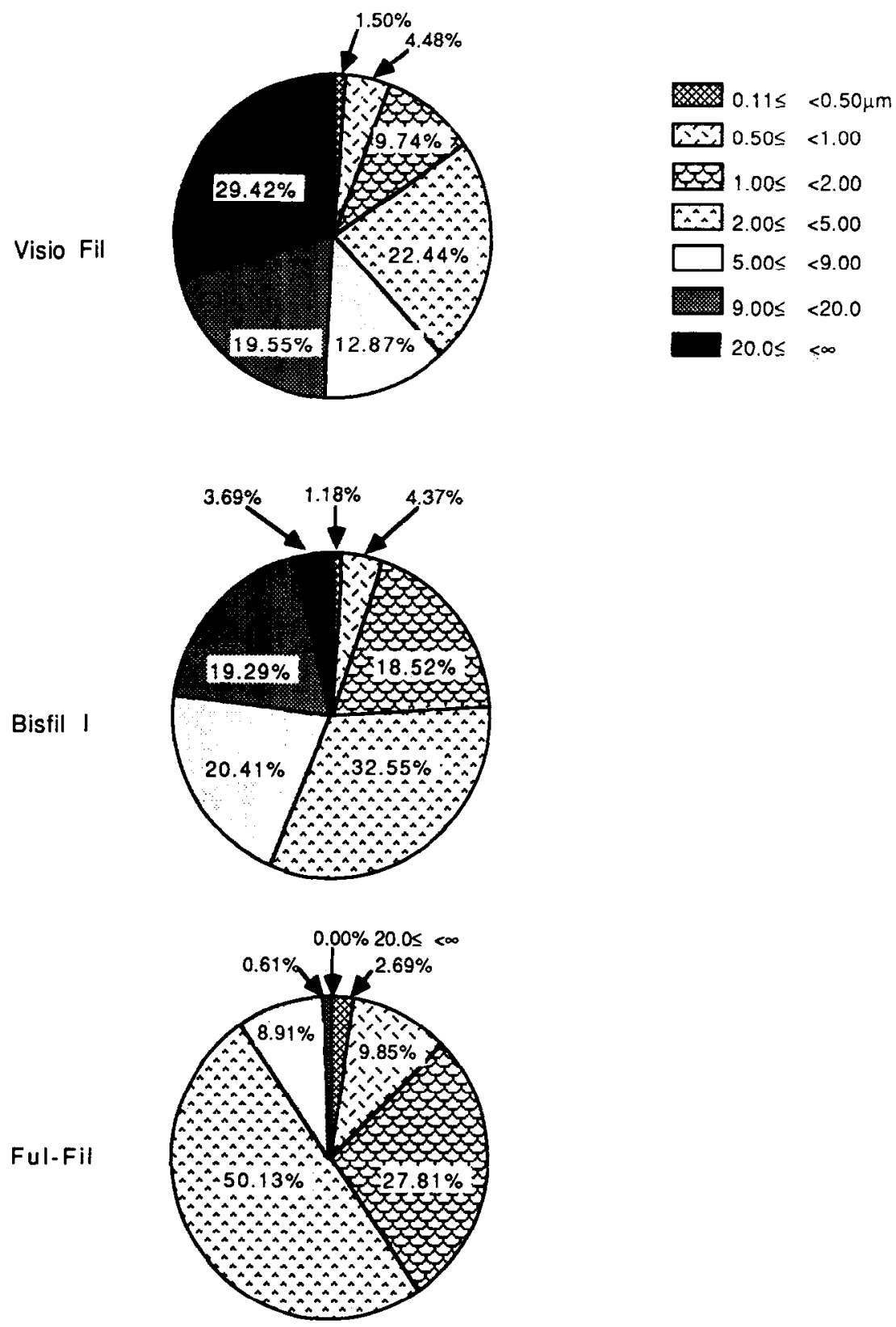

Fig. 7. Area occupied by the different size particles.

Table III. Tukey compromise test result on number differences

\begin{tabular}{llcl}
\hline & Vs. & Difference & \multicolumn{1}{c}{$\begin{array}{c}\text { Critical } \\
\text { diff erence }\end{array}$} \\
\hline \multirow{2}{*}{ Bisfil I } & Visio Fil & 259.683 & $209.254 \mathrm{~S}$ \\
& Ful-Fil & 422.635 & $228.375 \mathrm{~S}$ \\
Visio Fil & Ful-Fil & 162.952 & 209.254 \\
\hline
\end{tabular}

Effect:material; significance level, $0.05 ; \mathrm{S}$, significantly different at this level.

these classification systems; but again, this data is usually missing. In addition, when the specific gravity for the filler particles and the matrix are not discussed, percentage by weight and/or volume loses its significance. In this investi- gation three composite resins were initially selected for study on the basis of their classification as "fine particle." However, the qualitative results show a trend and the quantitative data demonstrated significant differences in the filler particle characterizations of these materials when examined by SEM and digital imaging.

Two ways of characterizing the filler particles content of composites were examined. The first was to measure the number of particles, and the second involved the measurement of the area occupied by the particles. Traditionally, the number of particles has been the primary method of describing composites, and the number has been tied to the average filler particles size. This implies that an actual count of the particles is recorded, and that the mean size of the particles was calculated from the data. 
Table IV. ANOVA table on area differences

\begin{tabular}{lrrrrrr}
\hline \multicolumn{1}{c}{ Source } & df & Sum of squares & Mean square & F-Value & P-Value & Error term \\
\hline Material & 2 & 32078136.347 & 0.000001604 & 65.729 & 0.0001 & Residual \\
Material , block & 6 & 1560336.414 & 260056.069 & 1.066 & 0.3911 & Residual \\
Site (block, material) & 18 & 6734528.309 & 374140.462 & 1.439 & 0.3432 & Material block \\
Area & 6 & 0.00000002173 & 0.0000003622 & 148.435 & 0.0001 & Residual \\
Material - area & 12 & 0.00000001555 & 12960859.610 & 53.114 & 0.0001 & Residual \\
Area - block - material & 36 & 38203967.883 & 1061221.330 & 2.836 & 0.0105 & Site block, material) \\
Area - site (material) & 36 & 16885828.341 & 469050.787 & 1.254 & 0.3101 & Site block, material) \\
Residual & 72 & 1569529.044 & 244021.223 & & & \\
\hline
\end{tabular}

Type I sums of squares.

In this study, the number of filler particles in each of the three composites were counted by the SEM and digital imaging system. Fig. 4 represents these actual counts for the seven groups as seen within the microscopic field under examination. The total mean number of particles for each material was calculated by adding together the mean filler particles in each of the seven groups. The total mean number of particles were 7991 for Ful-Fil, 6850 for Visio-Fil, and 5033 for BIS-FIL I composite resins. Based on the data, Ful-Fil had the largest total mean number of filler particles. Using the total mean number of particles as the basis for determining the percentage of fill, one might conclude that Ful-Fil was the most highly filled composite followed by BIS-FIL I and Visio-Fil.

In this study, the area occupied by filler particles and matrix in each of the three composites was also measured by SEM and the digital imaging system. In Fig. 5, if the seven groups are combined with the matrix, wc can determine the percentage of fill for each composite resin use this approach. The data indicated $55.26 \%$ fill for the Visio-Fil composite, $36.49 \%$ for BIS-FIL I, and $32.14 \%$ for Ful-Fil composite. Therefore, on the basis of total mean area occupied by the particles, one might conclude that Visio-Fil has the highest percentage of fill of the three composites, followed by BIS-FIL I and Ful-Fil, which is quite different from the previous method of using the total mean number of filler particles to determine the percentage of fill.

With the total mean number of particles and the total mean area occupied by these particles determined, a "true" mean filler particle size can be calculated for the first time. The mean filler particle size can be calculated by dividing the total mean area occupied by all the particles by the total mean number of particles. With this calculation method, the mean filler particle size was $2.31 \mu \mathrm{m}^{2}$ for Visio-Fil composite, $2.08 \mu \mathrm{m}^{2}$ for BIS-FIL I composite, and $1.15 \mu \mathrm{m}^{2}$ for Ful-Fil compositc. If one also assumes that these particles are spherical, the mean area $\left(\mu \mathrm{m}^{2}\right)$ can be converted to diameter $(\mu \mathrm{m})$ by establishing the mean filler particle size as $1.71 \mu \mathrm{m}$ for Visio-Fil composite, $1.62 \mu \mathrm{m}$ for BIS-FIL I composite, and $1.20 \mu \mathrm{m}$ for Ful-Fil composite. It would appear that little difference exists among the mean filler particle size among the three composites.

Nevertheless, the data clearly demonstrate significant
Table V. Tukey compromise test result on the area differences

\begin{tabular}{llll}
\hline & Vs. & Difference & $\begin{array}{c}\text { Critical } \\
\text { difference }\end{array}$ \\
\hline \multirow{2}{*}{ Ful-Fil } & Bisfil I & 178.581 & 193.426 \\
& Visio Fil & 949.438 & $211.101 \mathrm{~S}$ \\
\multirow{2}{*}{ Bisfil I } & Visio Fil & 770.857 & $193.426 \mathrm{~S}$ \\
\hline
\end{tabular}

Effect:material; significance level, $0.05 ; \mathrm{S}$, significantly different at this level

differences in the filler particle characterization of these composites. Recalling that the mean filler particle size previously calculated was greater than $1.2 \mu \mathrm{m}$ for all three composites $(1.71,1.62,1.2)$, one would expect the majority of filler particles to be greater than $1 \mu \mathrm{m}$. A mean particle size established by this method can be misleading as was found in Fig. 6, when more than $50 \%$ of the filler particle content of all three composites was particles smaller than $1 \mu \mathrm{m}$. For the Visio Fil material, $76.38 \%$ of its particles were smaller than $1 \mu \mathrm{m}$, followed by $71.04 \%$ for Ful-Fil and $60.57 \%$ for BIS-FIL I composite resins. Conversely, the number of larger particles $(>9 \mu \mathrm{m})$ was negligible for all three composites.

It has been reported that greater wear is observed with composite resins with larger filler particles. A greater percent filler of smaller particles has also been suggested as producing a composite with better wear resistance properties. Therefore, characterizing a composite in terms of the percentage of larger and smaller particle may be a more appropriate approach to their characterization. Because wear is a surface phenomenon, the area occupied by the particles as illustrated in Figs. 5 and 7 may be the method of characterizing the filler particle content of the composite. In Fig. 7, the surface area occupied by particles greater than $9 \mu \mathrm{m}$ was approximately $50 \%$ for Visio-Fil material, $20 \%$ for BISFIL I material, and approximately $1 \%$ for Ful-Fil material. Yet the number of particles greater than $9 \mu \mathrm{m}$ in Fig. 6 was less than $1 \%$ for all three composites. In Fig. 7 , it can be seen that the submicron particles occupied approximately $5 \%$ of the surface area for Visio. Fil and BISFIL I composites, and $12 \%$ for Ful-Fil composite. The number of these submicron particles in all three materials 
was greater than $50 \%$ as can be seen in Fig. 6 . Both of these findings are contrary to the initial description of these materials as fine particle by the commonly used methods of classification and classifying composites by mean filler particle size as determined by a series of calculations.

In reality these three composite resins were vastly different materials when the filler particle characterization was examined. All three composite resins are mixtures of various size groupings of filler particles. Figs. 5 and 7 more clearly illustrate the characterization of the filler particle content as a profile map based on the percentage of the number of particles by size groupings and the area occupied by the particles. The profile maps provide a graphic representation of the complexities of the surface of the composite resins, which ultimately play a major role in their wear resistance properties.

The findings of this investigation lead to questions about results on the property characteristics of composite resins where investigators have presented correlation tied to these earlier classification methods by use of the generic microfilled, fine particle, and blend systems. Our findings have demonstrated that calling a composite resin a "fine particle" material is not discriminatory enough in characterizing the filler particle content as a variable in the correlation. The availability of a profile map developed from SEM and digital imaging for a given composite resin provides investigators with a new means of examining potential relationships among the variables involved in composite resin formulations. With the profile map, many of the previously published reports should be revisited to determine whether the correlation hold true.

\section{CONCLUSIONS}

1. The three composite resin materials, BIS-FIL I, Visio-Fil and Ful-Fil, were significantly different $(p<0.0005)$ in the mean number of filler particles.

2 . The three composite resin materials were significantly different $(p<0.0005)$ in the mean area occupied by the filler particles.

3. The conventional classification as fine particle composite resin could not be justified for the three materials, BIS-FIL I, Visio-Fil and Ful-Fil, and the validity of such systems as a selection guide for the clinician is questioned.

4. Characterizing the filler particle content of a composite resin by using the profile map was found as a signifi- cantly better method than the previously used conventional methods of classification as microfilled, fine particle, and blends.

5. Scanning electron microscopy and digital imaging are valid and reliable methods to evaluate composite resins qualitatively and quantitatively for filler particle numbers, sizes, and the area occupied by the particles.

\section{REFERENCES}

1. Roulet. JF. Degradation of dental polymers. Basel: Karger, 1987;28-47.

2. Roulet JF. A materials scientist's view: assessment of wear and marginal integrity. Quint Intl 1987;18:543-52.

3. Leinfelder KF. Wear patterns and rates of posterior composite resins. Int Dent J 1987;37:152-7.

4. Swift EJ Jr. Wear of composite resins in permanent posterior teeth. J Am Dent Assoc 1987;115:584-8.

5. Bryant RW. Posterior composite resin restorations-a review of clinical problems. Aust Prosthodont J 1987;1:41-50.

6. Leinfelder KF. Composite resins: properties and clinical performance. In: O'Brien WJ, ed. Dental materials: properties and selection. Chicago: Quintessence Publ, 1989;139-57.

7. Crumpler DC, Heymann HO, Shugars DA, Bayn SC, Leinfelder KF. Five-year clinical investigation of one conventional composite and three microfilled resins in anterior teeth. Dent Mater 1988;4:217-22.

8. Lutz F, Phillips RW. A classification and evaluation of composite resin systems. J Prosthet DenT 1983;50:480-8.

9. Hosada $H$, Toshimoto $Y$, Shigehisa I. SEM and elemental analysis of composite resins. J Prosthet Dent 1990;64:669-76.

10. Marshall GW Jr, Marshall SJ, Buyne SC. Restorative dental materials: scanning electron microscopy and $\mathrm{x}$-ray microanalysis. Scanning $\mathrm{Mi}$ crose 1988;2:2007-28.

11. Farah JW, Powers JM. The Dental Advisor: Materials, Instruments and Equipment Quarterly. 1984;1:2.

12. Farah JW, Powers JM. The Dental Advisor: Materials, Instruments and Equipment Quarterly. 1986;3:2.

13. Phillips RW. Past, present, and future composite resin systems. Dent Clin North Am 1981;25:209.

14. Digital image analysis of materials. Technical bulletin. Princeton, NJ: Princeton Gamma-Tech, Inc., 1990.

15. Bowen RL. Dental filling material comprising vinyl silane treated fused silica and a binder consisting of a reaction product of bisphenol and glycidyl acrylate. U.S. Patent: 3,006,112, November 1962.

Reprint requests to:

DR. MERLE J. JAARDA

DEPARTMENT OF PRosthodon'tics

SCHOOL OF DENTISTRY

UNIVERSITY OF MICHIGAN

1011 NoRTH UNIVERSITY ST.

ANN ARBOR, MI 48109-1078

\section{Contributing author}

Charles J. Kowalski, MS, PhD, Professor, Department of Biologic and Materials Sciences, University of Michigan School of Dentistry, Ann Arbor, Mich. 